\title{
INFRAESTRUTURA \\ ESCOLAR: UM CRITÉRIO \\ DE COMPARAÇÃO \\ DA QUALIDADE NA \\ EDUCAÇÃO INFANTIL
}

BRUNO TOVAR FALCIANO

EDSON CORDEIRO DOS SANTOS

MARIA FERNANDA REZENDE NUNES

\section{RESUMO}

Este artigo se propõe a sugerir um grupo de indicadores que possibilite analisar comparativamente a qualidade da infraestrutura entre diferentes estabelecimentos de educação infantil das redes públicas. o desafio que nos propusemos foi o de responder a perguntas tais como: seria possível avaliar a qualidade de toda uma rede de ensino? De que forma comparamos diferentes instituições, a fim de que se possa priorizar e maximizar os recursos públicos empregados? Há indicadores que possam ser objetivamente mensuráveis e utilizados em qualquer universo de estudo? O texto apresenta uma das muitas possibilidades de respostas, propondo, a partir do exemplo de dois municípios, indicadores de qualidade para a verificação da infraestrutura que podem ser aplicados a todas as instituições de educação infantil no Brasil.

PALAVRAS-CHAVE INDICADORES EDUCACIONAIS - EDUCAÇÃO INFANTIL・ QUALIDADE DO ENSINO. 


\section{INFRAESTRUCTURA ESCOLAR: UN CRITERIO DE COMPARACIÓN DE LA CALIDAD EN LA EDUCACIÓN INFANTIL}

RESUMEN

Este artículo se propone sugerir un grupo de indicadores que posibilite analizar comparativamente la calidad de la infraestructura entre diferentes establecimientos de educación infantil de las redes públicas. El desafío que nos propusimos fue el de responder a preguntas como: ¿sería posible evaluar la calidad de toda una red de enseñanza? ¿De qué forma comparamos distintas instituciones, a fin de poder priorizar y maximizar los recursos públicos utilizados? ¿Hay indicadores que pueden ser objetivamente mensurables y empleados en cualquier universo de estudio? La investigación presenta una de las muchas posibilidades de respuestas y propone, a partir del ejemplo de dos municipios, indicadores de calidad para verificar la infraestructura que pueden aplicarse a todas las instituciones de educación infantil en Brasil.

PALABRAS CLAVE INDICADORES EDUCACIONALES • EDUCACIÓN INFANTIL • CALIDAD DE LA ENSEÑANZA • INFRAESTRUCTURA ESCOLAR.

\section{SCHOOL INFRASTRUCTURE: A CRITERION FOR COMPARING QUALITY IN EARLY CHILDHOOD EDUCATION}

ABSTRACT

This article aims to suggest a group of indicators useful to analyze in a comparative way the quality of infrastructure of early childhood facilities in the public school system. The challenge we set for ourselves was to answer questions such as: would it be possible to assess the quality of an entire school system? How do we compare different institutions in order to prioritize and maximize the public resources invested? Are there indicators that can be measured objectively and used in any educational environment? The study presents one of many possible answers, proposing quality indicators for checking the infrastructure, which can be applied to all the institutions of child-care education in Brazil, based on the example of two municipalities.

KEYWORDS EDUCATIONAL INDICATORS - EARLY CHILDHOOD EDUCATION • EDUCATIONAL QUALITY • SCHOOL INFRASTRUCTURE. 
O espaço físico não apenas contribui para a realização da educação, mas é em si uma forma silenciosa de educar. (Antonio Vinão Frago, 1998)

1 Entendemos ser importante distinguir a relação entre indicadores e parâmetros de qualidade. Parâmetros são referenciais balizadores do conceito de qualidade, enquanto indicadores são instrumentos de quantificação desses referenciais. A natureza dos parâmetros é ser mais abrangente e genérica; já os indicadores precisam ser objetivos, precisos e quantificáveis, a fim de que se possa aferir a aplicação dos parâmetros.
Este trabalho se propõe a sugerir um grupo de indicadores ${ }^{1}$ que possibilite analisar comparativamente a qualidade da infraestrutura entre diferentes estabelecimentos de educação infantil das redes públicas dos municípios de Nova Iguaçu e Belford Roxo, localizados no estado do Rio de Janeiro. Espera-se que esse critério seja de fácil implementação e que permita a qualquer interessado construir uma escala de qualidade semelhante, a fim de priorizar possíveis intervenções de melhoria na rede pública de ensino.

$\mathrm{O}$ desafio que nos propusemos foi o de responder a perguntas tais como: seria possível avaliar a qualidade de toda uma rede de ensino? De que forma comparamos diferentes instituições, a fim de que se possa priorizar e maximizar os recursos públicos empregados? Há indicadores que possam ser objetivamente mensuráveis e utilizados em qualquer universo de estudo? Com o intuito de ampliar as discussões nesse tema, este texto apresenta uma das muitas possibilidades de respostas a essas questões, propondo, a partir do exemplo de dois municípios, indicadores de qualidade para a verificação da infraestrutura que podem ser aplicados a todas as instituições de educação infantil no Brasil. 
Com a aprovação da Emenda Constitucional n. 59 (BRASIL, 2009a), que amplia a obrigatoriedade do ensino, que passa a ser dos 4 aos 17 anos, a educação infantil se depara com um novo momento. Quais as condições e a organização dos municípios para atender a essa demanda de expansão? Quais os impactos dessa expansão na gestão e na organização do sistema? Como garantir o direito da criança ao atendimento de qualidade? Em pesquisa realizada por Kramer, Nunes e Corsino (2011), foi possível observar, nos municípios do estado do Rio de Janeiro, diferentes formas de expansão das redes. Surgiram desde iniciativas mais efetivas, como a construção de novos espaços para a educação infantil, até iniciativas precárias e emergenciais, como o uso de espaços alternativos: aluguel de casas, prédios comerciais, aproveitamento de salas em escolas de ensino fundamental, buscando adaptá-las. Esses espaços são realmente adequados para receber as crianças pequenas?

O primeiro item deste artigo traz uma aproximação do universo da pesquisa, justificando a importância da produção de indicadores para a expansão de matrículas da educação infantil; em seguida, o texto aborda as opções teóricas sobre o conceito de qualidade tomadas pelo estudo. $\mathrm{O}$ item "Indicadores de qualidade da infraestrutura de educação infantil: propondo um modelo de análise comparativa" traz a metodologia empregada para avaliar a infraestrutura escola da rede municipal de dois municípios do estado do Rio de Janeiro, bem como os impactos da expansão da educação infantil na rede física das escolas municipais. Por fim, são apresentadas considerações acerca do universo encontrado e subsídios para medidas políticas a serem adotadas no processo de expansão.

\section{APROXIMAÇÃO DO UNIVERSO DE ESTUDO}

A pesquisa "Repercussões das políticas de educação infantil no estado do Rio de Janeiro: o programa Proinfância e as estratégias municipais de atendimento a crianças de 0 a 6 anos" (SANTOS; NUNES; FALCIANO, 2015), em sua investigação nos municípios da região metropolitana, apontou como maior desafio, segundo os gestores municipais, o aten- 
2 O Programa Nacional de Reestruturação e Aquisição de Equipamentos para a Rede Escolar Pública de Educação Infantil (Proinfância) foi criado pelo Governo Federal com a premissa de que a construção de creches e pré-escolas e a aquisição de equipamentos para a rede física escolar desse níve educacional são indispensáveis à melhoria da qualidade da educação (BRASIL, 2007)

3 Até julho de 2013, o Rio de Janeiro contava com dez unidades em funcionamento.

4 Censo Demográfico de 2010 (INSTITUTO BRASILEIRO DE GEOGRAFIA E ESTATISTICA IBGE, 2010)

5 O percentual de crianças na préescola foi calculado considerando a proporção de matrículas na préescola (BRASIL, 2014) dividida pela população de crianças de 4 e 5 anos de idade (IBGE, 2010)

6 Censo Escolar 2010/2014 (BRASIL, 2014) dimento às especificidades do Programa Proinfância ${ }^{2}$ para a construção de um equipamento escolar, destacando terrenos, espaço físico, padrões de medidas, apropriação/desapropriação e escritura. Tais dificuldades podem ser percebidas pelo baixo número de unidades em funcionamento no estado. ${ }^{3}$ No rastro de perceber como a indução de políticas pela união é apreendida pelo poder local, essa pesquisa cobriu todas as unidades em funcionamento no Rio de Janeiro e destacou ainda os poucos brinquedos disponíveis, principalmente para a faixa de 4 e 5 anos, que são quase inexistentes, e um investimento expressivo em cartazes com as letras do alfabeto e números, presentes desde o berçário, suscitando concepções equivocadas acerca do processo de apropriação da linguagem escrita por crianças pequenas. Os espaços de acesso às salas, corredores de entrada e murais internos e externos são ornamentados com motivos relacionados à preparação para a escrita, com lápis gigantes, muitas letras e números, inclusive nas salas da creche (de 0 a 3 anos).

Muitas crianças ainda não têm acesso à educação infantil: a falta de vagas nas redes, a dificuldade de locomoção, a pouca flexibilidade do atendimento, a oscilação do mercado de trabalho nas exigências de escolaridade dos pais são desafios apontados em uma série de estudos e provocam a busca de medidas alternativas.

Nesse sentido, a partir desses resultados, buscamos compreender como a mesorregião metropolitana do Rio de Janeiro, composta por 30 municípios, organizou o atendimento das crianças. Para fins deste texto, escolhemos uma amostra de municípios levando em conta os seguintes critérios: baixo atendimento à pré-escola em 2010 e maior e menor expansão em número de matrículas no período de 2010-2014 nessa etapa. Nesse cenário, selecionamos os seguintes municípios: a) Nova Iguaçu, com 65.468 crianças de 0 a 5 anos, ${ }^{4}$ um percentual de atendimento à pré-escola de $43 \%$ em $2010,{ }^{5}$ e expansão de matrículas de 55\% no período 2010-2014; ${ }^{6}$ b) Belford Roxo, com 40.252 crianças de 0 a 5 anos, um percentual de atendimento de 48\% à pré-escola em 2010, e expansão de 19\% de matrículas no período 2010-2014. Ambos têm uma população total de mais de 200 mil habitantes, um PIB 
(Produto Interno Bruto) per capita em torno de 10 mil reais e matrículas das crianças na pré-escola de aproximadamente $45 \%$, o que significa dizer que esses municípios partem de condições próximas em 2010 e chegam ao ano de 2014 com resultados educacionais (cobertura do atendimento) bastante diferenciados.

Espera-se que essa amostra dos estabelecimentos municipais de educação infantil desses dois municípios permita a construção de uma relação ordenada da qualidade de infraestrutura dos estabelecimentos, a fim de subsidiar, por exemplo, a priorização de possíveis intervenções de melhoria na rede escolar.

Temos claro que o Censo Escolar do Instituto Nacional de Estudos e Pesquisas Educacionais Anísio Teixeira (Inep), realizado anualmente com informações de estabelecimentos da educação básica de todo o país, representa um importante suporte técnico para a formulação e a avaliação das políticas educacionais e nos será de grande valia na construção dos indicadores propostos neste estudo.

\section{A EXPANSÃO DA EDUCAÇÃO INFANTIL: IMPLICAÇÕES PARA A QUALIDADE DOS ESPAÇOS}

No Brasil, há muitos documentos elaborados tendo como foco a qualidade na educação infantil, ${ }^{7}$ principalmente com o objetivo de induzir as gestões municipais à formulação de políticas públicas que gerem mudanças nas realidades que não estiverem adequadas com o que preceituam. Por qualidade tomam como ponto de partida as considerações de Dahlberg, Moss e Pence (2003, p. 119), que afirmam que esse "é um conceito construído socialmente, com significados muito particulares, produzidos por meio do que chamamos de 'o discurso da qualidade'”. O discurso da qualidade, segundo os autores, fomenta tentativas de aplicação, gerando “pesquisas, medidas, padrões e diretrizes sobre a boa prática” (DAHLBERG; MOSS; PENCE, 2003, p. 132). Assim, desenvolvem-se critérios, avaliações e indicadores das instituições, para verificar seu desempenho. Contudo, apesar de terem sido formulados documentos orientadores, com a participa-
7 Formulados no âmbito do Ministério da Educação, contamos com quatro importantes documentos, produzidos na primeira década do século XXI, que versam sobre a qualidade na educação infantil: a) Indicadores da qualidade na educação infantil (BRASIL, 2009b) - instrumento de autoavaliação da qualidade das instituições de educação infantil, por meio de um processo participativo e aberto a toda a comunidade: b) Monitoramento do uso dos indicadores da qualidade na educação infantil (BRASIL, 2011) - documento elaborado com vistas a contribuir com as Secretarias Municipais de Educação no aprimoramento de ações que possam identificar a qualidade das condições e do trabalho realizado nos estabelecimentos educacionais e apontar elementos para sua melhor qualificação; c) Parâmetros nacionais de qualidade para a educação infantil (BRASIL, 2006b) - referências de qualidade para a educação infantil a serem utilizadas pelos sistemas educacionais, que promovam a igualdade de oportunidades educacionais e levem em conta diferenças, diversidades e desigualdades do país e das muitas culturas nele existentes:

d) Parâmetros básicos de infra-estrutura para instituições de educação infantil (BRASIL, 2006a) - estudos e parâmetros nacionais relacionados à qualidade dos ambientes das instituições de educação infantil para que estes se tornem promotores de aventuras, descobertas, desafios, aprendizagem e facilitem as interações. 
ção de vários gestores municipais, apenas isso não se mostra suficiente para garantir sua adequada incorporação às políticas municipais.

É possível afirmar que, atualmente, os maiores desafios da educação infantil são: expandir a cobertura do atendimento e melhorar a qualidade. A relação entre esses dois desafios é indissociável. Afinal, para que a cobertura do atendimento aumente, é necessário dispor de espaço físico adequado para as crianças pequenas. Assim, concordamos com Romano e Heringer (2011, p. 9), que nos trazem que "não basta ter belas políticas no papel, elas têm que ser bem implementadas para que cumpram com seus objetivos". Ou seja, mesmo tendo a política pública de educação infantil já instituída, não podemos nos contentar, precisamos analisar como vem se dando essa expansão do atendimento, em termos principalmente de qualidade.

Nos pressupostos de Cury (2008, p. 16), a educação escolar "apresenta-se como um direito juridicamente protegido". Entretanto, o autor acentua que "do direito nascem as exigências de cobrar uma efetivação de qualidade" (2008, p. 17). Ressalta que

[...] o caminho ainda é longo, pois a busca da qualidade não pode nem se abster de lutar por maior igualdade no campo da distribuição da renda e da riqueza e nem de propugnar por alterações no interior dos sistemas de ensino. (CURY, 2008, p. 17)

Com a aprovação da Constituição Federal (BRASIL, 1988) e a posterior aprovação, na década seguinte, de diversas leis regulamentadoras, a educação infantil incorpora novas referências legais, passando a se constituir como a primeira etapa da educação básica, com atendimento em creche, para crianças de 0 a 3 anos, e pré-escola, para crianças de 4 e 5 anos. Desfrutando dessa nova fase legal, passa a possuir meta nos Planos Nacionais de Educação (PNEs) (BRASIL, 2001, 2014) aprovados pelo Congresso Nacional.

No ano de 2009, temos a aprovação da Emenda Constitucional n. 59/2009 (BRASIL, 2009a), que, entre outras deliberações, coloca a educação pré-escolar (4 e 5 anos de idade) como direito subjetivo, ou seja, como educação 
obrigatória, com universalização prevista até 2016, referendada posteriormente pela aprovação da Lei n. 12.796/2013 (BRASIL, 2013). A passagem da pré-escola como direito subjetivo é ponto focal desse texto, já que preconiza que, até o ano de 2016, todas as crianças de 4 e 5 anos têm que acessar essa etapa educacional.

Pelas questões apresentadas acima, essa é uma questão importante no desenvolvimento desta investigação, que, para além do processo de ampliação do atendimento na educação infantil, pretende atuar na qualidade da infraestrutura nas instituições de educação infantil.

Contudo, quando falamos de qualidade, do que estamos falando? O que é realmente qualidade? Como avaliar a qualidade na educação? Como poderíamos inferir que uma determinada infraestrutura escolar é de qualidade? Será que o que, para uns, é visto como de qualidade, para outros também será? O que já foi de qualidade algum dia permanece de qualidade nos dias de hoje?

Não há uma resposta única para todas essas questões e sabemos que não existe consenso absoluto sobre padrões de qualidade, principalmente em se tratando da qualidade na educação, pois a própria educação é o reflexo de um momento histórico, de uma sociedade, de uma cultura, de um povo, de um país, dentre outros contextos.

Relacionamos nossa conceituação de qualidade com os pressupostos de Dahlberg, Moss e Pence (2003, p. 87), que afirmam que "as instituições dedicadas à primeira infância são socialmente construídas. [...] Para que elas servem, a questão de seu papel e do seu propósito, não são auto-evidentes.” Eles concluem: "elas são o que nós "como comunidade de agentes humanos' [originada da nossa interação ativa com outras pessoas e com a sociedade] fazemos dela" (DAHLBERG; MOSS; PENCE, 2003, p. 87).

A educação infantil é a única etapa que vem brindada (e também blindada) com o nome educação; as demais são ensinos. Temos, assim, conforme acentuam Dahlberg, Moss e Pence (2003, p. 114), a criança sendo

[...] capaz de aprender desde o nascimento, cuja aprendizagem durante a primeira infância é uma parte de um proces- 
Campos e Cruz (2006, p. 14), baseados nos pressupostos de Peter Moss e no contexto europeu de onde o autor é proveniente, trazem-nos de forma sumária que "a qualidade é um conceito relativo, baseado em valores; [sendo] um processo dinâmico e contínuo que requer revisões, já que nunca chega a um enunciado definitivo". As autoras têm a clareza de considerar que, no caso brasileiro, ainda não existe um patamar mínimo de qualidade nas unidades de educação infantil. Alertam-nos também sobre as condições adversas de muitos estabelecimentos dedicados à educação infantil, as quais podem afetar os direitos básicos das crianças pequenas, bem como colocar em risco o seu desenvolvimento físico, psicológico e como ser social. Elas enfatizam que

[...] o equilíbrio entre a preocupação com a igualdade e a
preocupação com o respeito às diferenças nem sempre é
fácil de alcançar, ainda mais em um país marcado por tantas
desigualdades como o nosso. (CAMPOS; CRUZ, 2006, p. 15)

8 Segundo a Meta 1 do PNE (2014/2024), todas as crianças de 4 e 5 anos de idade devem estar matriculadas em uma instituição escolar até o ano de 2016.
Para os municípios estudados, permanece o duplo desafio: o primeiro, referente à expansão do atendimento; e o segundo, à melhoria da qualidade do serviço ofertado. Vejamos: a) Nova Iguaçu apresentava um atendimento de $43 \%$ das crianças de 4 e 5 anos em 2010 e ampliou o número de matrículas nessa etapa em 55\% no período de 2010-2014; b) o município de Belford Roxo atendia a $48 \%$ das crianças de 4 e 5 anos em 2010 e obteve um aumento de 19\% no número de matrículas nessa etapa no período de 2010-2014, ainda longe de atingir a meta do PNE. ${ }^{8} \mathrm{~A}$ tabela a seguir demonstra o número de estabelecimentos que atendem à educação infantil nesses municípios. 
TABELA 1 - Número de estabelecimentos municipais que atendiam à educação infantil em 2013, segundo o tipo de atendimento, nos dois municípios fluminenses estudados

\begin{tabular}{|c|c|c|}
\hline \multirow{2}{*}{ TIPO DE ATENDIMENTO } & \multicolumn{2}{|c|}{ MUNICÍPIO } \\
\hline & NOVA IGUAÇU & BELFORD ROXO \\
\hline Educação infantil e outras etapas & 90 & 32 \\
\hline \multicolumn{3}{|l|}{ Exclusivamente educação infantil } \\
\hline Apenas creche & 1 & 6 \\
\hline Apenas pré-escola & 3 & 1 \\
\hline Creche e pré-escola & 13 & 9 \\
\hline Total & 17 & 16 \\
\hline Total & 107 & 48 \\
\hline
\end{tabular}

Fonte: Tabulação própria a partir do Censo Escolar da Educação Básica do Inep de 2013.

A expansão das redes tem ocorrido de diferentes maneiras, que vão desde iniciativas mais efetivas, como a construção de novos espaços escolares para a educação infantil, até iniciativas precárias e emergenciais, como o uso de espaços alternativos: aluguel de casas, prédios comerciais, aproveitamento de salas em escolas de ensino fundamental (buscando adaptá-las para atender as crianças menores). Neste último caso, as turmas de educação infantil, quase sempre, são colocadas em espaços ruins e separadas das crianças maiores. As crianças acabam ficando em espaços que não foram construídos para serem escolas de educação infantil, que foram adaptados e não têm condições de recebê-las (TOLEDO et al., 2011).

Em seu estudo, Vieira (2011, p. 255) apontou alguns riscos relacionados à qualidade do atendimento da educação infantil, tais como:

[...] de excluir o cuidado, pela diminuição da oferta de atendimento em tempo integral; de antecipar a escolaridade com as características da oferta do ensino fundamental; da cisão creche-pré-escola; e de privatização da creche.

A autora conclui que

[...] a obrigatoriedade escolar estendida à pré-escola deve significar, mais que uma imposição às famílias, um meio de propiciar uma universalização que oportunize experiências 
No item a seguir, investigamos possíveis implicações desse processo no âmbito da universalização da pré-escola e da expansão da creche.

\section{INDICADORES DE QUALIDADE DA INFRAESTRUTURA DE EDUCAÇÃO INFANTIL: PROPONDO UM MODELO DE ANÁLISE COMPARATIVA}

É possível propor diversos indicadores com o intuito de avaliar a qualidade da infraestrutura escolar, seja em seus aspectos construtivos, de material ou equipamentos, seja visando a contemplar toda a complexidade do processo educativo e adequá-los às particularidades de cada sistema educacional. Porém, fazem parte das dificuldades recorrentes no monitoramento de indicadores de qualidade: o custo de levantamento dos dados, a periodicidade da amostra, a necessidade de tabulação das informações obtidas e os problemas presentes na padronização de certas variáveis.

Assim sendo, nossa opção, como premissa deste estudo, foi que os indicadores a serem trabalhados fossem obtidos a partir de dados já existentes, de domínio público, divulgados regularmente e de abrangência nacional. Com esses norteadores em mente, identificamos que a melhor fonte de informação seria a base do Censo Escolar da Educação Básica do Inep, que consiste em:

[...] uma pesquisa declaratória realizada anualmente pelo MEC/INEP/DEEB em parceria com as Secretarias de Educação estaduais e municipais, que levanta informações estatístico-educacionais sobre a educação básica brasileira. Nesta pesquisa são coletados dados educacionais, tanto sobre a infraestrutura da escola, como sobre o pessoal docente, matrículas, jornada escolar, rendimento e movimento escolar, por nível, etapa e modalidade de ensino, dentre outros. 
essenciais para a realização de análises e estudos comparados, subsidiando a formulação de políticas públicas para distribuição dos recursos como o Fundo de Manutenção e Desenvolvimento da Educação Básica e de Valorização dos Profissionais da Educação (Fundeb) (Lei n. 11.494, de 20 de junho de 2007), quando é a base de dados oficial para o cálculo dos recursos a serem repassados aos estados e municípios. Os dados do Censo Escolar são a principal referência para a gestão de programas federais, tais como: Programa Nacional do Livro Didático - PNLD, Programa Nacional de Alimentação Escolar - PNAE, Programa Nacional de Apoio ao Transporte Escolar - PNAT, Programa Dinheiro Direto na Escola - PDDE, Programa de Informatização das Escolas - Proinfo, dentre outros. (INSTITUTO BRASILEIRO DE GEOGRAFIA E ESTATÍSTICA, 2016)

Ainda sobre o Censo Escolar da Educação Básica do Inep, destaca-se que está organizado em quatro grandes tabelas (escola, matrículas, turmas e docentes), totalizando, só para o ano de 2013, uma amostra com 433 variáveis e mais de 69 milhões de registros. As principais variáveis de cada tabela são:

- Escola: situação e local de funcionamento; caracterização da infraestrutura (abastecimento de água, energia elétrica, etc.); disponibilidade de equipamentos didáticos/pedagógicos; existência de dependências físicas; fornecimento de alimentação escolar; oferta de atendimento educacional especializado; disponibilidade de materiais didáticos de atendimento à diversidade sociocultural.

- Turma: horário de funcionamento; tipo de atendimento; existência de atividade complementar; atendimento educacional especializado; tipo de disciplinas.

- Alunos: idade; sexo; cor ou raça; uso de transporte escolar; necessidade educacional especial; rendimento escolar (aprovado/reprovado).

- Docentes: idade; sexo; cor ou raça; escolaridade; função que exerce na escola; turma em que atua; disciplina que leciona. 
9 É foco deste estudo o uso das variáveis que poderiam contribuir para uma avaliação da qualidade da infraestrutura, mas nada impede que novos indicadores de qualidade sejam agregados em trabalhos futuros.
De todas essas 433 variáveis disponíveis para o ano de 2013, identificamos que havia 60 itens de infraestrutura e nestes foram realizadas as seguintes adequações: ${ }^{9}$

- seis variáveis foram descartadas pela falta da possibilidade de se estabelecer uma relação direta com um parâmetro de qualidade. Exemplo disso é a variável que trata da existência ou não de lavanderia no estabelecimento;

- 23 variáveis foram consolidadas em sete novas variáveis, pois as suas informações eram complementares. Por exemplo, foi criada uma única variável - ID_ENERGIA -, que identifica o abastecimento ou não de energia elétrica, em vez de utilizar as variáveis disponíveis que indicam se o abastecimento é realizado pela rede pública, por gerador ou outras fontes de energia;

- 12 variáveis que se referiam à quantidade de equipamentos foram adequadas para informar apenas se havia ou não esses equipamentos na instituição;

- em substituição às variáveis que tratam da quantidade total de computadores e da quantidade de computadores administrativos, foi criada uma única variável que trata apenas da presença ou não de outros computadores, além daqueles disponibilizados aos alunos.

Após esse primeiro tratamento, restaram 40 variáveis, que foram agrupadas em sete categorias, de acordo com a relação entre elas, originando, então, sete diferentes indicadores de qualidade de infraestrutura escolar. O quadro a seguir demonstra a composição de cada um desses indicadores e, nos anexos 1 e 2, é possível conhecer o detalhamento de todas as variáveis utilizadas. 
QUADRO 1 - Composição dos Indicadores da Qualidade da Infraestrutura Escolar propostos no estudo

\begin{tabular}{|c|c|c|}
\hline INDICADOR & DESCRIÇÃO & VARIÁVEIS \\
\hline Infraestrutura Básica & $\begin{array}{l}\text { Trata do fornecimento ou não de água, } \\
\text { luz, esgoto e água filtrada. }\end{array}$ & $\begin{array}{l}\text { ID_AGUA, ID_ENERGIA, ID_ESGOTO, } \\
\text { ID_SANITARIO, ID_AGUA_FILTRADA }\end{array}$ \\
\hline Estrutura Pedagógica & $\begin{array}{l}\text { Verifica a existência de estruturas que } \\
\text { contribuem para a vivência educativa. }\end{array}$ & $\begin{array}{l}\text { ID_BIBLIOTECA, ID_QUADRA_- } \\
\text { ESPORTES, ID_AREA_VERDE, } \\
\text { ID_PATIO, ID_LABORATORIO_-_ERIO_ } \\
\text { INFORMATICA, ID_LABORATORIO_ } \\
\text { CIENCIAS }\end{array}$ \\
\hline Adequação à Educação Infantil & $\begin{array}{l}\text { Verifica a existência de instalações } \\
\text { próprias da educação infantil, como } \\
\text { berçários, sanitários adaptados, } \\
\text { parquinho e banheiro com chuveiro. }\end{array}$ & $\begin{array}{l}\text { ID_BERCARIO, ID_SANITARIO_EI, } \\
\text { ID_PARQUE_INFANTIL, ID_BANHEIRO_ } \\
\text { CHUVEIRO }\end{array}$ \\
\hline $\begin{array}{l}\text { Adequação às Necessidades } \\
\text { Especiais }\end{array}$ & $\begin{array}{l}\text { Verifica a existência de instalações } \\
\text { próprias para o atendimento } \\
\text { especializado, como área de circulação, } \\
\text { banheiros, mobiliário e salas com } \\
\text { materiais pedagógicos específicos. }\end{array}$ & $\begin{array}{l}\text { ID_DEPENDENCIAS_PNE, } \\
\text { ID_SANITARIO_PNE, ID_SALA__ } \\
\text { ATENDIMENTO_ESPECIAL }\end{array}$ \\
\hline Estrutura Predial & $\begin{array}{l}\text { Verifica as demais estruturas } \\
\text { administrativas necessárias ao bom } \\
\text { funcionamento do estabelecimento. }\end{array}$ & $\begin{array}{l}\text { ID_SALA_DIRETORIA, ID_SALA_- } \\
\text { PROFESSOR, ID_SECRETARIA, } \\
\text { ID_AUDITORIO, ID_ALMOXARIFADO, } \\
\text { ID_DESPENSA, ID_COZINHA, ID_- } \\
\text { REFEITORIO }\end{array}$ \\
\hline $\begin{array}{l}\text { Equipamentos de Apoio } \\
\text { Pedagógico }\end{array}$ & $\begin{array}{l}\text { Verifica a existência de equipamentos } \\
\text { que contribuem para a vivência } \\
\text { educativa. }\end{array}$ & $\begin{array}{l}\text { NUM_EQUIP_TV, NUM_EQUIP_DVD, } \\
\text { NUM_EQUIP_SOM, NUM_EQUIP-_ } \\
\text { MULTIMIDIA, NUM_EQUIP_FOTO, } \\
\text { NUM_COMP_ALUNOS, ID_ACESSO_- } \\
\text { INTERNET }\end{array}$ \\
\hline Equipamentos Diversos & $\begin{array}{l}\text { Verifica a existência de equipamentos } \\
\text { que contribuam ao bom funcionamento } \\
\text { do estabelecimento. }\end{array}$ & $\begin{array}{l}\text { ID_COMPUTADORES_OUTROS, } \\
\text { NUM_EQUIP_PARABOLICA, NUM_- } \\
\text { EQUIP_COPIADORA, NUM_EQUIP_- } \\
\text { IMPRESSORA, NUM_EQUIP_FAX, } \\
\text { NUM_EQUIP_VIDEOCASSETE, NUM_- } \\
\text { EQUIP_RETRO }\end{array}$ \\
\hline
\end{tabular}

Fonte: Tabulação própria com base nas variáveis do Censo Escolar da Educação Básica do Inep de 2013.

Sem que fosse estabelecida qualquer ponderação sobre os itens que compõem cada indicador, assumiu-se a seguinte escala de classificação: a) quando nenhum item de um determinado indicador é atendido, esse indicador é classificado como desatendido (D); b) quando até a metade dos itens de um indicador é atendido, esse indicador é classificado como insatisfatório (I); c) quando mais da metade dos itens de um indicador é atendido, esse indicador é classificado como satisfatório (S); d) quando a totalidade dos itens de um indicador é atendida, esse indicador é classificado como atendido (A).

Utilizando a amostra de 155 estabelecimentos, que é o total de estabelecimentos de educação infantil da rede públi- 
ca municipal de Nova Iguaçu e Belford Roxo para o ano de 2013, aplicamos, então, essa escala de classificação aos sete indicadores propostos anteriormente. Os resultados obtidos são apresentados na tabela a seguir.

TABELA 2 - Distribuição absoluta e relativa dos estabelecimentos municipais que atendiam à educação infantil em 2013 nos dois municípios considerados, para cada indicador, segundo a classificação proposta no estudo

\begin{tabular}{|c|c|c|c|c|c|c|c|c|c|c|}
\hline \multirow{3}{*}{$\begin{array}{l}\text { INDICADOR } \\
\text { Infraestrutura Básica }\end{array}$} & \multicolumn{8}{|c|}{$\begin{array}{l}\text { ESCALA DE CLASSIFICAÇÃO DOS ESTABELECIMENTOS } \\
\text { DE EDUCAÇÃO INFANTIL DA REDE MUNICIPAL }\end{array}$} & & \\
\hline & \multicolumn{2}{|c|}{ DESATENDIDO } & \multicolumn{2}{|c|}{ INSATISFATÓRIO } & \multicolumn{2}{|c|}{ SATISFATÓRIO } & \multicolumn{2}{|c|}{ ATENDIDO } & \multicolumn{2}{|c|}{ TOTAL } \\
\hline & 0 & O\% & 0 & O\% & 9 & $6 \%$ & 146 & $94 \%$ & 155 & $100 \%$ \\
\hline Estrutura Pedagógica & 64 & $41 \%$ & 38 & $25 \%$ & 28 & $18 \%$ & 25 & $16 \%$ & 155 & $100 \%$ \\
\hline $\begin{array}{l}\text { Adequação à Educação } \\
\text { Infantil }\end{array}$ & 9 & $6 \%$ & 95 & $61 \%$ & 46 & $30 \%$ & 5 & $3 \%$ & 155 & $100 \%$ \\
\hline $\begin{array}{l}\text { Adequação às } \\
\text { Necessidades Especiais }\end{array}$ & 39 & $25 \%$ & 103 & $66 \%$ & 10 & $6 \%$ & 3 & $2 \%$ & 155 & $100 \%$ \\
\hline Estrutura Predial & 0 & O\% & 39 & $25 \%$ & 105 & $68 \%$ & 11 & $7 \%$ & 155 & $100 \%$ \\
\hline $\begin{array}{l}\text { Equipamentos de } \\
\text { Apoio Pedagógico }\end{array}$ & 3 & $2 \%$ & 41 & $26 \%$ & 59 & $38 \%$ & 52 & $34 \%$ & 155 & $100 \%$ \\
\hline Equipamentos Diversos & 4 & $3 \%$ & 79 & $51 \%$ & 69 & $45 \%$ & 3 & $2 \%$ & 155 & $100 \%$ \\
\hline
\end{tabular}

Fonte: Tabulação própria a partir a partir do Censo Escolar da Educação Básica do Inep de 2013.

Pela tabela, pode-se observar, por exemplo, que, nos estabelecimentos analisados, o indicador Infraestrutura Básica é atendido por quase toda a amostra, enquanto o indicador Estrutura Pedagógica está, na maioria das vezes, desatendido, e indicadores como Adequação à Educação Infantil e Adequação às Necessidades Especiais sinalizam um atendimento insatisfatório.

\section{PRIORIZAÇÃO DE INDICADORES E RESULTADOS DAS UNIDADES PÚBLICAS DA AMOSTRA}

Até este ponto do trabalho, não foi atribuído qualquer critério de valor ou julgamento na avaliação dos itens ou indicadores de infraestrutura. O percurso realizado até então foi o de: a) realizar um estudo detalhado do Censo Escolar da Educação Básica do Inep para identificar variáveis que poderiam sugerir uma avaliação das condições de qualidade 
de infraestrutura; b) adequar essas variáveis à proposta do trabalho onde algumas foram consolidadas, outras substituídas e outras descartadas; c) agrupar as variáveis remanescentes, construindo-se, assim, indicadores pelo critério de pertinência; d) propor uma escala de classificação para os indicadores; e, por fim, d) classificar os estabelecimentos da amostra de acordo com a escala de cada um dos indicadores.

O intuito deste trabalho, porém, é o de realizar uma relação ordenada que aponte para a priorização de ações de melhoria da qualidade da infraestrutura na rede de ensino e, para tanto, é necessário estabelecer a importância comparativa de contribuição de cada indicador para o processo de aprendizagem. Nesse sentido, adotamos a seguinte lógica de priorização:

- é primordial que qualquer local de ensino possa oferecer minimamente uma infraestrutura básica como água, luz, esgoto, banheiros e água filtrada;

- a estrutura que contribui diretamente para o processo pedagógico é mais relevante do que as demais estruturas físicas de apoio;

- deve-se privilegiar a oferta de equipamentos de uso pedagógico em relação aos demais equipamentos;

- a não adequação dos estabelecimentos às particularidades da educação infantil pode restringir o acesso dessas crianças ao seu direito básico à educação;

- a não acessibilidade desses estabelecimentos às particularidades daqueles que necessitam de atendimento especial pode restringir o acesso destes ao seu direito básico à educação.

O passo seguinte foi, portanto, estabelecer notas para a escala de classificação e ponderar uma nota final, estabelecendo diferentes pesos para cada um dos indicadores. As notas atribuídas para a escala foram as seguintes: zero para os indicadores desatendidos, um para os que apresentaram atendimento insatisfatório, dois para os atendidos satisfatoriamente e a nota máxima de três para aqueles atendidos. Os pesos das notas dos indicadores seguiram a lógica de priorização apresentada anteriormente e receberam os seguintes valores: um para o indicador Equipamentos Diversos, dois tanto para os 
10 ○ critério adotado para estabelecimento destes pesos foi o de atribuir a ponderação de um para o indicador de menor importância e, em seguida, dobrar esse valor para os indicadores subsequentes Sugerimos a adequação desses pesos em outros estudos, caso haja necessidades indicadores de Estrutura Predial quanto para o de Equipamento de Apoio Pedagógico, quatro para os indicadores Estrutura Pedagógica, Adequação à Educação Infantil e Adequação às Necessidades Especiais e, por fim, oito para o indicador Infraestrutura Básica. ${ }^{10}$ Para ficar claro como se determinou a nota de cada estabelecimento, a Tabela 3 descreve a nota atribuída a um estabelecimento hipotético, seguindo esse critério.

particulares.

TABELA 3 - Exemplo do cálculo da nota final de um estabelecimento hipotético utilizando o critério de classificação e a ponderação sugeridos

\begin{tabular}{l|c|c|c|c}
\hline INDICADOR & $\begin{array}{c}\text { CLASSIFICAÇÃO } \\
\text { NA ESCALA }\end{array}$ & $\begin{array}{c}\text { NOTA NA } \\
\text { ESCALA }\end{array}$ & $\begin{array}{c}\text { PESO DO } \\
\text { INDICADOR }\end{array}$ & $\begin{array}{c}\text { NOTA X } \\
\text { PESO }\end{array}$ \\
\hline Infraestrutura Básica & atendido & 3 & 8 & 24 \\
\hline Estrutura Pedagógica & insatisfatório & 1 & 4 & 4 \\
\hline $\begin{array}{l}\text { Adequação à } \\
\text { Educaçăo Infantil }\end{array}$ & desatendido & 0 & 4 & 0 \\
\hline $\begin{array}{l}\text { Adequação às } \\
\text { Necessidades Especiais }\end{array}$ & atendido & 3 & 4 & 12 \\
\hline Estrutura Predial & insatisfatório & 1 & 2 & 2 \\
\hline $\begin{array}{l}\text { Equipamentos de } \\
\text { Apoio Pedagógico }\end{array}$ & atendido & 3 & 2 & 6 \\
\hline Equipamentos Diversos & satisfatório & 2 & 1 & 2 \\
\hline Nota final & & & & 50 \\
\hline
\end{tabular}

Fonte: Tabulação própria a partir do critério de indicadores propostos.

Uma vez atribuída uma nota para cada um dos estabelecimentos, elaboramos uma lista em ordem crescente da menor para a maior nota, na qual a menor nota é daquele estabelecimento que possuiu, segundo os indicadores propostos, a menor adequação aos critérios de qualidade de infraestrutura para o atendimento escolar e a maior nota é daquele que já está mais adequado a esses mesmos critérios. Na Tabela 4, a seguir, é apresentado um resumo com os 20 estabelecimentos de menor nota de cada município, os quais, portanto, encontram-se entre aqueles que, de acordo com os indicadores propostos, mais necessitam de intervenção de melhoria. 


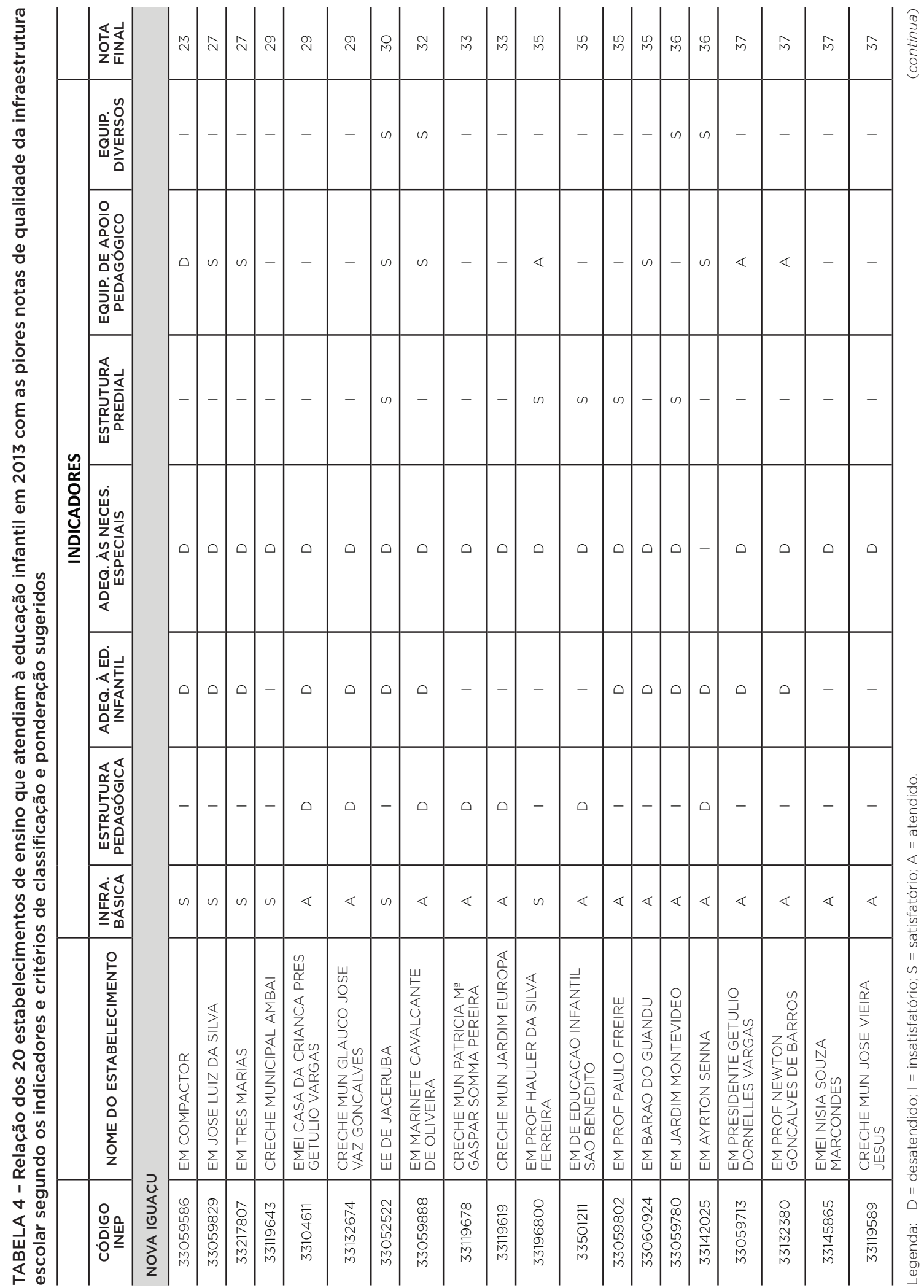




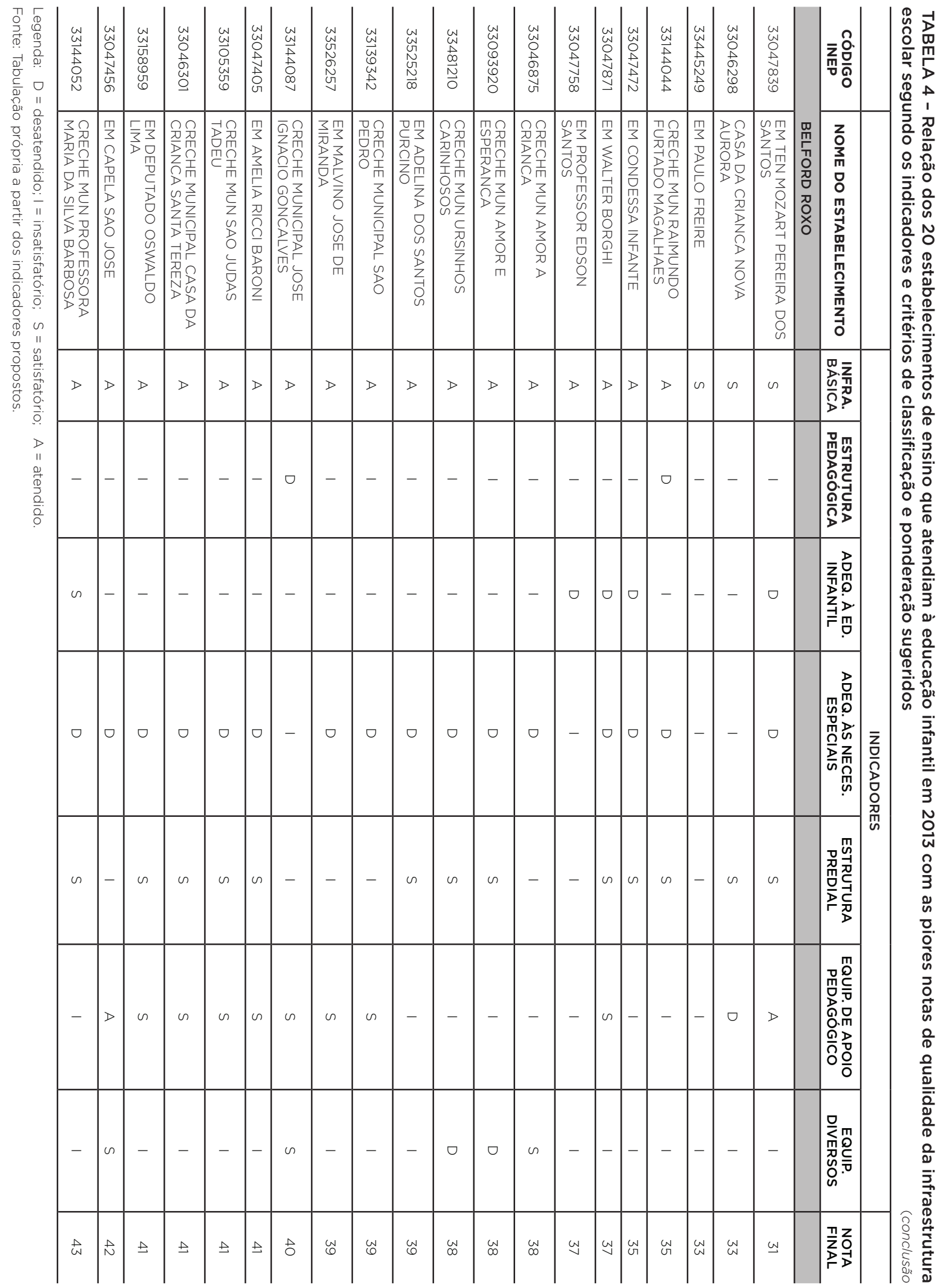


Das 20 unidades que mais necessitam de melhorias de infraestrutura escolar em Nova Iguaçu, constata-se que sete são exclusivas de educação infantil (cinco de creche e duas de pré-escola). Destaca-se também que 13 estão desatendidas quanto ao indicador Adequação à Educação Infantil e sete estão insatisfatoriamente atendidas nesse mesmo aspecto. Já em Belford Roxo, das 20 unidades com maiores necessidades de melhorias da infraestrutura escolar, dez são de estabelecimentos exclusivos de educação infantil, o que nos permite dizer que, além da expansão estar sendo feita a passos lentos, a qualidade dessa expansão é bastante questionável. Os indicadores Adequação à Educação Infantil e Estrutura Pedagógica neste último município são desatendidos ou insatisfatórios em 19 das 20 unidades da amostra.

\section{ALGUMAS CONSIDERAÇÕES}

Mesmo levando-se em conta que o conceito de qualidade sofre mudanças de acordo com a época, a história e o contexto nacional, regional ou local, não podemos deixar de considerar a infraestrutura dos estabelecimentos escolares como sendo um dos fatores preponderantes na busca da qualidade na educação infantil, já que temos claro que o espaço físico também educa e que ter acesso a uma infraestrutura de qualidade constitui um direito de todas as crianças.

A organização desses indicadores de qualidade de infraestrutura escolar, levada a termo neste artigo, subsidia os gestores públicos no estabelecimento de prioridades para as ações de melhoria, levando-se em conta os fatores que mais ou menos afetam os processos educativos. Nesse sentido, a metodologia utilizada para o levantamento das unidades escolares e o lugar que cada uma delas ocupa na oferta de uma infraestrutura de qualidade, sem dúvida, pode ser utilizada em qualquer rede municipal, estadual, federal ou privada.

É importante considerar algumas limitações no estudo proposto neste artigo. A primeira relaciona-se às variáveis disponíveis, que são obtidas no Censo Escolar da Educação Básica do Inep como já dadas, sem possibilidades de novas perguntas e/ou aprofundamentos. A segunda refere-se à 
impossibilidade de verificação das variáveis disponíveis nas unidades de ensino, pois os seus registros são feitos pelos próprios dirigentes e/ou gestores diretamente no Sistema do Censo Escolar, o que pode alterar algumas informações, tendo em vista o que cada um considera como uma variável atendida ou não atendida.

Também não podemos deixar de dizer que, sendo a proposta de caráter quantitativo, necessitamos que outros olhares mais qualitativos se somem à discussão, tornando a proposta mais completa, na busca da melhoria da qualidade do atendimento das crianças pequenas.

\section{REFERÊNCIAS}

BRASIL. Congresso Nacional. Constituição da República Federativa do Brasil de 1988. Brasília, DF, 1988. Disponível em: <http://www.planalto.gov.br/ ccivil_03/Constituicao/Constitui\%C3\%A7ao.htm>. Acesso em: 5 mar. 2012.

BRASIL. Congresso Nacional. Lei n. 10.172, de 9 de janeiro de 2001. Aprova o Plano Nacional de Educação e dá outras providências. Brasília, DF, 2001. Disponível em: <http://www.planalto.gov.br/ccivil_03/leis/leis_2001/110172. htm>. Acesso em: 23 mar. 2012.

BRASIL. Congresso Nacional. Emenda Constitucional n. 59, de 11 de novembro de 2009. Acrescenta $\S 3^{\circ}$. ao art. 76 do Ato das Disposições Constitucionais Transitórias para reduzir, anualmente, a partir do exercício de 2009, o percentual da Desvinculação das Receitas da União incidente sobre os recursos destinados à manutenção e desenvolvimento do ensino de que trata o art. 212 da Constituição Federal, dá nova redação aos incisos I e VII do art. 208 , de forma a prever a obrigatoriedade do ensino de quatro a dezessete anos e ampliar a abrangência dos programas suplementares para todas as etapas da educação básica, e dá nova redação ao $§ 4^{\circ}$. do art. 211 e ao $\S 3^{\circ}$. do art. 212 e ao caput do art. 214, com a inserção neste dispositivo de inciso VI. Brasília, DF, 2009a. Disponível em: <http://www.planalto.gov.br/ccivil_03/constituicao/ emendas/emc/emc59.htm>. Acesso em: 5 mar. 2012.

BRASIL. Congresso Nacional. Lei n. 12.796, de 04 de abril de 2013. Altera a Lei n. 9.394, de 20 de dezembro de 1996, que estabelece as diretrizes e bases da educação nacional, para dispor sobre a formação dos profissionais da educação e dar outras providências. Brasília, DF, 2013. Disponível em: <http://www.legisweb.com.br/legislacao/?legislacao=253025>. Acesso em: 5 maio 2013.

BRASIL. Congresso Nacional. Lei n. 13.005, de 25 de junho de 2014. Aprova o Plano Nacional de Educação - PNE e dá outras providências. Brasília, DF, 2014. Disponível em: <http://www.planalto.gov.br/ccivil_03/_Ato20112014/2014/Lei/L13005.htm.> Acesso em: 1 fev. 2015. 
BRASIL. Instituto Nacional de Estudos e Pesquisas Educacionais Anísio Teixeira. Base de microdados do Censo Escolar da Educação Básica. Brasília, DF: Inep, 2014. Disponível em: <http://portal.inep.gov.br/basica-levantamentosacessar>. Acesso em: 30 mar. 2015.

BRASIL. Ministério de Educação. Indicadores da qualidade na educação infantil. Brasília, DF: MEC/SEB, 2009b. Disponível em: <http://portal.inep.gov.br/ basica-levantamentos-acessar>. Acesso em: 30 mar. 2015.

BRASIL. Ministério de Educação. Parâmetros básicos de infra-estrutura para instituições de educação infantil. Brasília, DF: MEC/SEB, 2006a. 45 p.; il.

BRASIL. Ministério de Educação. Parâmetros nacionais de qualidade para a educação infantil. Brasília, DF: MEC/SEB, 2006b. v. 1, v. 2; il.

BRASIL. Ministério de Educação. Monitoramento do uso dos indicadores da qualidade na educação infantil: resumo executivo. São Paulo: Ação Educativa, 2011. Disponível em: <http://portal.mec.gov.br/index.php?option=com docman\&task=doc_download\&gid=13120\&Itemid=>. Acesso em: 28 jan. 2015.

BRASIL. Ministério da Educação/ FNDE. Resolução n. 6, de 24 de abril de 2007. Estabelece as orientações e diretrizes para execução e assistência financeira suplementar ao Programa Nacional de Reestruturação e Aquisição de Equipamentos para a Rede Escolar Pública de Educação Infantil Proinfância, 2007.

CAMPOS, Maria Malta; CRUZ, Silvia Helena Vieira (Rel.). Consulta sobre qualidade da educação infantil: o que pensam e querem os sujeitos deste direito. São Paulo: Cortez, 2006.

CURY, Carlos Roberto Jamil. Políticas públicas de educação e desigualdade. In: FÉRES, Maria José Vieira et al. Textos complementares para formação de gestores. Brasília, DF: ProJovem Urbano, 2008.

DAHLBERG, Gunilla; MOSS, Peter; PENCE, Alan. Qualidade na educação da primeira infância: perspectivas pós-modernas. Tradução de Magda França Lopes. Porto Alegre: Artmed, 2003.

FRAGO, Antônio Viñao; ESCOLANO, Agustín. Currículo, espaço e subjetividade: a arquitetura como programa. 2. ed. Rio de Janeiro: DP\&A, 1998. 152 p.

INSTITUTO BRASILEIRO DE GEOGRAFIA E ESTATÍSTICA. Base de Dados Metadados: Inep - Educação Básica. 2016. Disponível em: < http://ces.ibge.gov. br/base-de-dados/metadados/inep/educacao-basica>. Acesso em: 28 jan. 2015.

INSTITUTO BRASILEIRO DE GEOGRAFIA E ESTATÍSTICA. Censos Demográficos: Tabela 200 - População residente por sexo, situação e grupos de idade Amostra - Características Gerais da População. 2010. Disponível em:

$<$ http://www.sidra.ibge.gov.br/bda/tabela/listabl.asp?z=cd\&o=2\&i=P\&c=200>. Acesso em: 9 abr. 2014.

NUNES, Maria Fernanda Rezende; CORSINO, Patrícia; DIDONET, Vital. Educação infantil no Brasil: primeira etapa da educação básica. Brasília, DF: Unesco, 2011. 
ROMANO, Jorge; HERINGER, Rosana. Recuperando experiências de monitoramento de política pública por organizações da sociedade civil. In: ROMANO, Jorge; HERINGER, Rosana. (Org.). A política vivida: olhar crítico sobre monitoramento de políticas públicas. 1. ed. Rio de Janeiro: Ford Foundation, 2011.

SANTOS, Edson Cordeiro dos; NUNES, Maria Fernanda Rezende; FALCIANO, Bruno Tovar. As políticas públicas indutoras e o programa Proinfância. In: NUNES, Maria Fernanda Rezende (Coord.). Proinfância e as estratégicas municipais de atendimento a crianças de 0 a 6 anos. Rio de Janeiro: Traço \& Cultura, 2015.

TOLEDO, Maria Leonor Pio Borges de; NUNES, Maria Fernanda Rezende; CORSINO, Patrícia; SIQUEIRA, Rejane. Condições da educação infantil nas redes municipais: entre arranjos e soluções. In: NUNES, Maria Fernanda Rezende; CORSINO, Patrícia; KRAMER, Sônia. Relatório de pesquisa: educação infantil e formação de profissionais no estado do Rio de Janeiro (1999-2009). Rio de Janeiro: Traço e Cultura, 2011.

VIEIRA, Lívia Maria Fraga. Obrigatoriedade escolar na educação infantil. Revista Retratos da Escola, Brasília, DF, v. 5, n. 9, p. 245-262, jul./dez. 2011.

BRUNO TOVAR FALCIANO

Mestrando em Educação na Universidade Federal do Estado do Rio de Janeiro (Unirio), Rio de Janeiro, Rio de Janeiro, Brasil bruno@tovar.com.br

\section{EDSON CORDEIRO DOS SANTOS}

Doutorando em Educação na Universidade Federal do Estado do Rio de Janeiro (Unirio), Rio de Janeiro, Rio de Janeiro, Brasil edsoncordeiro.nig@gmail.com

MARIA FERNANDA REZENDE NUNES

Professora doutora do Programa de Pós-graduação em Educação da Universidade Federal do Estado do Rio de Janeiro (PGEdu/Unirio), Rio de Janeiro, Rio de Janeiro, Brasil nunes.mariafernandarezende@gmail.com 


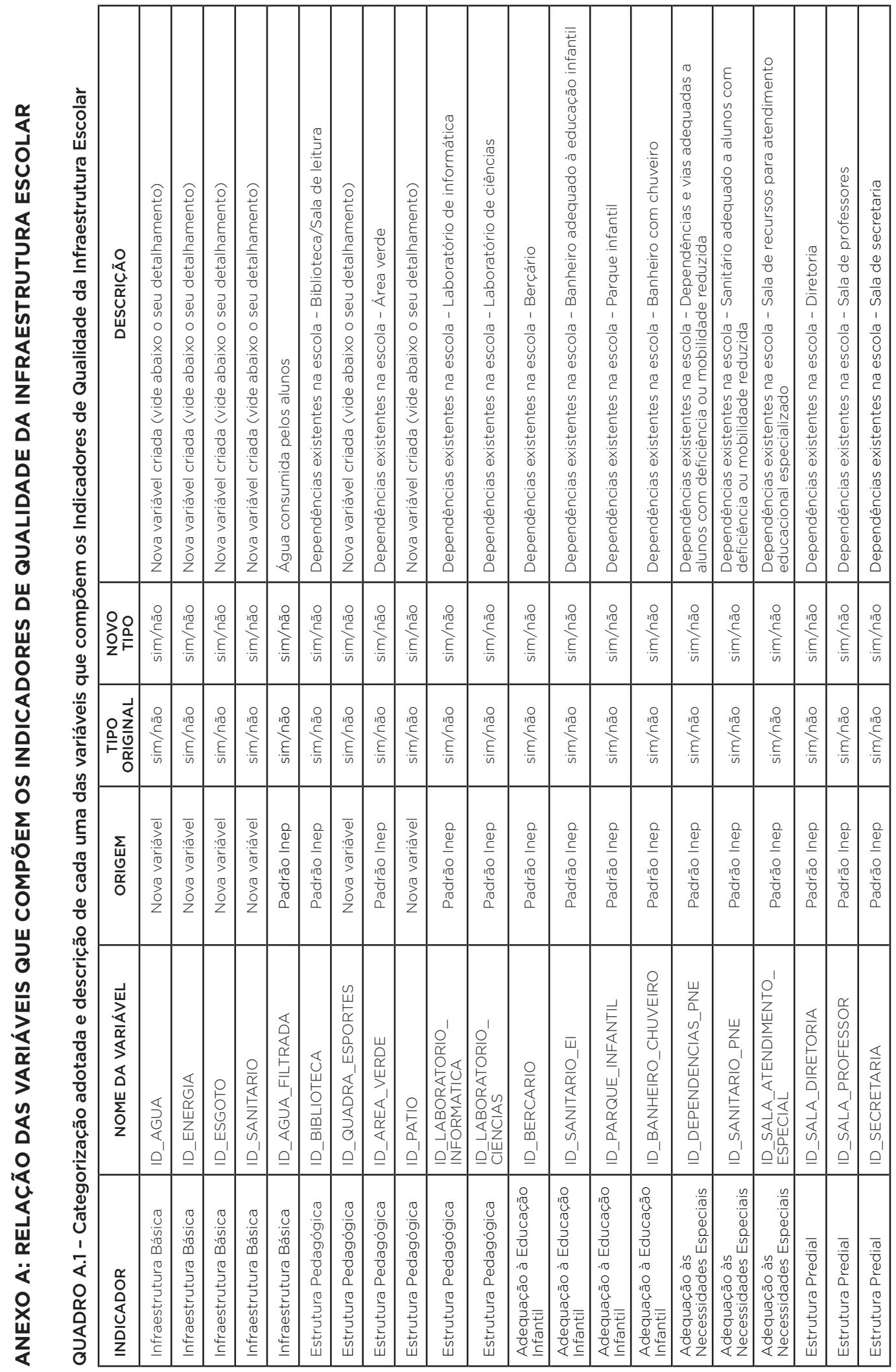




\begin{tabular}{|c|c|c|c|c|c|c|c|c|c|c|c|c|c|c|c|c|c|c|c|}
\hline 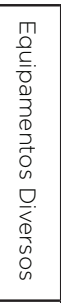 & 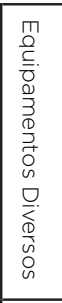 & 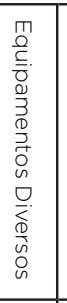 & 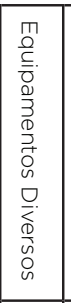 & 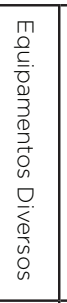 & 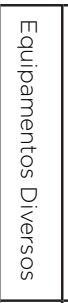 & 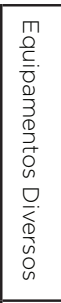 & 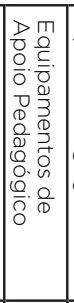 & 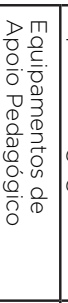 & 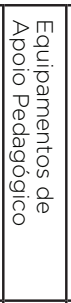 & 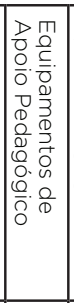 & 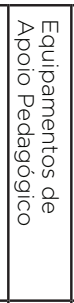 & 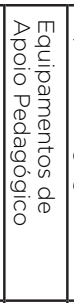 & 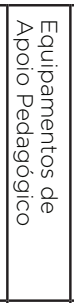 & 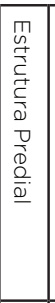 & 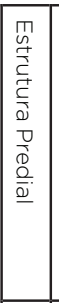 & 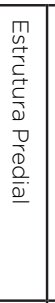 & 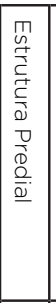 & 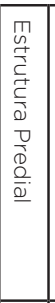 & 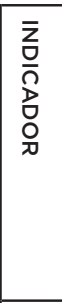 \\
\hline 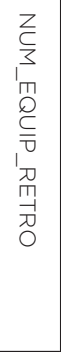 & 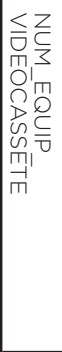 & 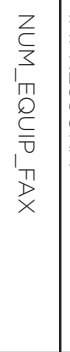 & 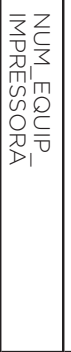 & 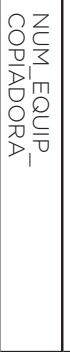 & 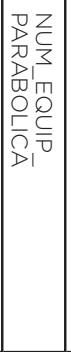 & 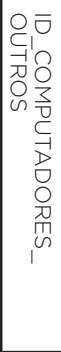 & 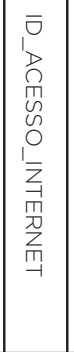 & 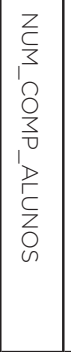 & 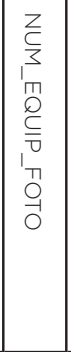 & 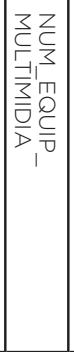 & 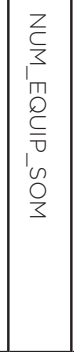 & 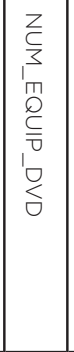 & 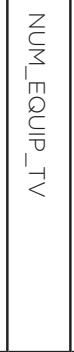 & 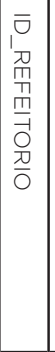 & 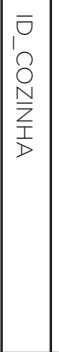 & 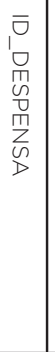 & 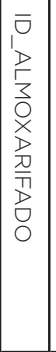 & 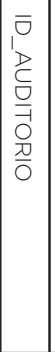 & 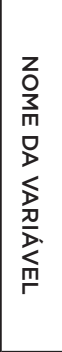 \\
\hline 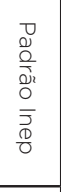 & 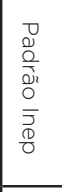 & 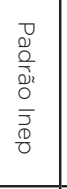 & 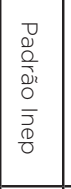 & 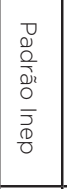 & 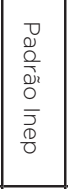 & 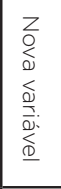 & 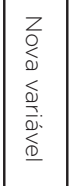 & 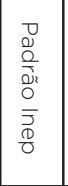 & 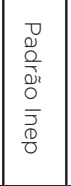 & 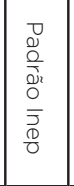 & 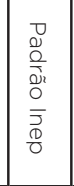 & 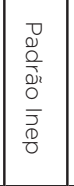 & 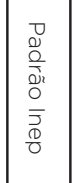 & 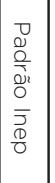 & 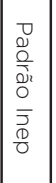 & 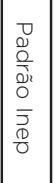 & 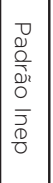 & 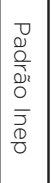 & 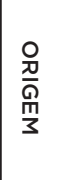 \\
\hline 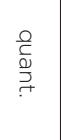 & 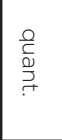 & 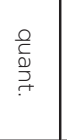 & 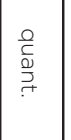 & 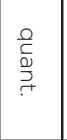 & 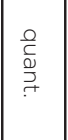 & 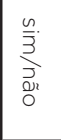 & 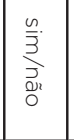 & 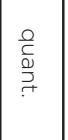 & 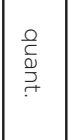 & 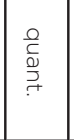 & 足 & 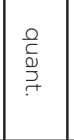 & 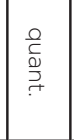 & 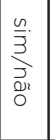 & 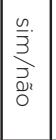 & 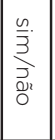 & 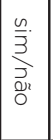 & 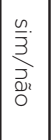 & 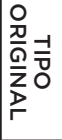 \\
\hline 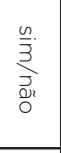 & 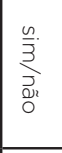 & 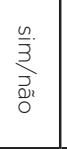 & 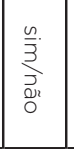 & 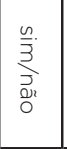 & 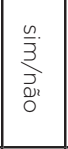 & 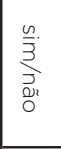 & 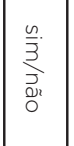 & 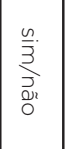 & 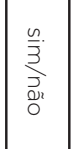 & 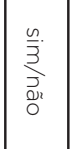 & 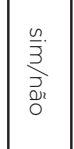 & 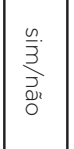 & 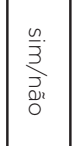 & 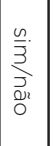 & 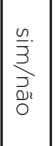 & 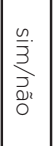 & 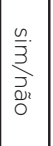 & 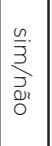 & 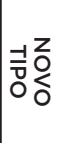 \\
\hline 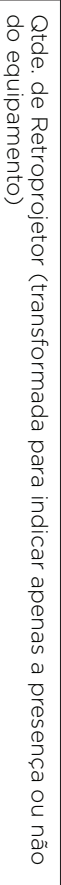 & 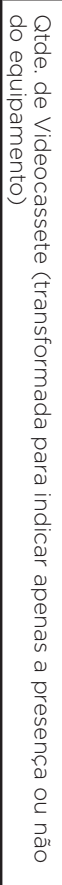 & 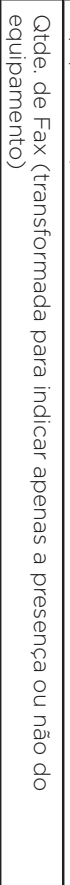 & 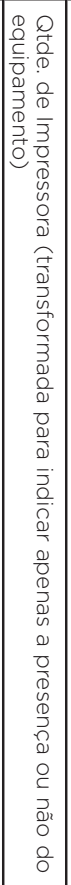 & 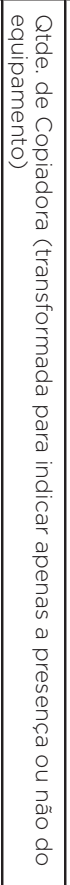 & 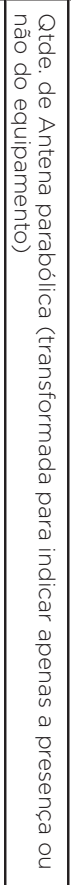 & 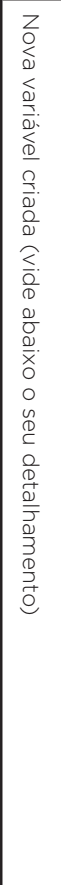 & 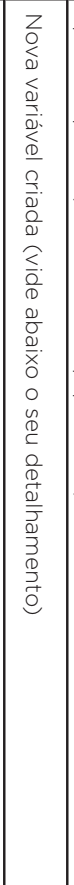 & 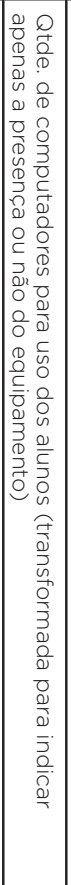 & 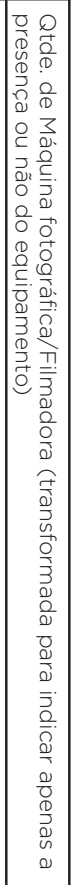 & 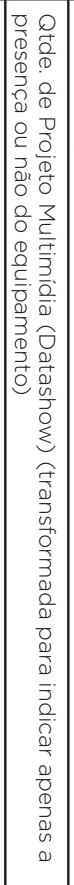 & 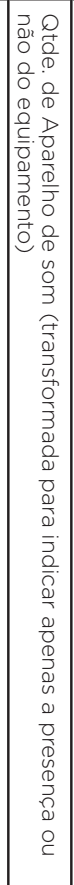 & 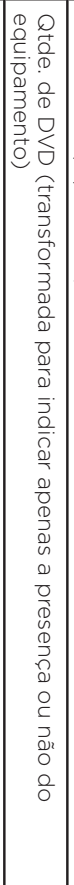 & 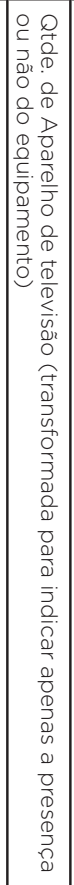 & 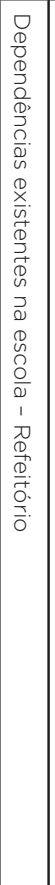 & 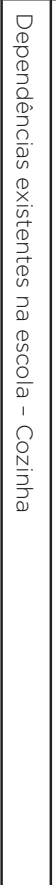 & 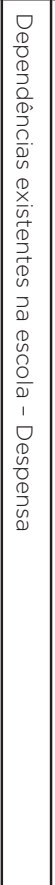 & 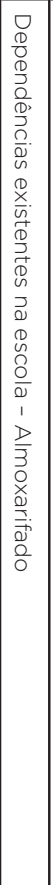 & 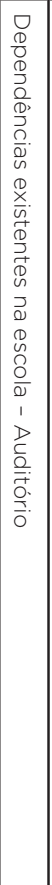 & 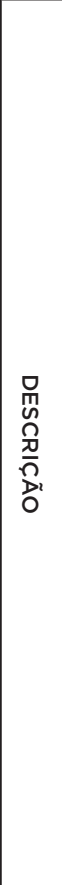 \\
\hline
\end{tabular}




\section{ANEXO B: RELAÇÃO DAS VARIÁVEIS QUE FORAM CRIADAS E QUE FORAM DESCARTADAS NA COMPOSIÇÃO DOS INDICADORES DE QUALIDADE DA INFRAESTRUTURA ESCOLAR}

QUADRO B.1 - Composição, categorização e descrição de cada uma das variáveis que foram criadas para compor os Indicadores de Qualidade da Infraestrutura Escolar

\begin{tabular}{|c|c|c|c|c|c|}
\hline $\begin{array}{l}\text { NOME DA } \\
\text { NOVA } \\
\text { VARIÁVEL }\end{array}$ & $\begin{array}{l}\text { VARIÁVEIS QUE A } \\
\text { COMPÕEM }\end{array}$ & ORIGEM & $\begin{array}{l}\text { TIPO } \\
\text { ORIGINAL }\end{array}$ & $\begin{array}{l}\text { NOVO } \\
\text { TIPO }\end{array}$ & DESCRIÇÃO \\
\hline \multirow{5}{*}{ ID_AGUA } & ID_AGUA_REDE_PUBLICA & $\begin{array}{l}\text { Padrão } \\
\text { Inep }\end{array}$ & $\operatorname{sim} /$ não & sim/não & $\begin{array}{l}\text { Abastecimento de água - } \\
\text { Rede pública }\end{array}$ \\
\hline & $\begin{array}{l}\text { ID_AGUA_POCO_ } \\
\text { ARTESIANNO }\end{array}$ & $\begin{array}{l}\text { Padrão } \\
\text { Inep }\end{array}$ & sim/não & sim/não & $\begin{array}{l}\text { Abastecimento de água - } \\
\text { Poço artesiano }\end{array}$ \\
\hline & ID_AGUA_CACIMBA & $\begin{array}{l}\text { Padrão } \\
\text { Inep }\end{array}$ & sim/não & sim/não & $\begin{array}{l}\text { Abastecimento de água - } \\
\text { Cacimba/Cisterna/Poço }\end{array}$ \\
\hline & ID_AGUA_FONTE_RIO & $\begin{array}{l}\text { Padrão } \\
\text { Inep }\end{array}$ & $\operatorname{sim} /$ não & sim/não & $\begin{array}{l}\text { Abastecimento de água - } \\
\text { Fonte/Rio/Igarapé/Riacho/ } \\
\text { Córrego }\end{array}$ \\
\hline & ID_AGUA_INEXISTENTE & $\begin{array}{l}\text { Padrão } \\
\text { Inep }\end{array}$ & sim/não & sim/não & $\begin{array}{l}\text { Abastecimento de água - } \\
\text { Inexistente }\end{array}$ \\
\hline \multirow{4}{*}{ ID_ENERGIA } & $\begin{array}{l}\text { ID_ENERGIA_REDE_ } \\
\text { PUBLICA }\end{array}$ & $\begin{array}{l}\text { Padrão } \\
\text { Inep }\end{array}$ & sim/não & sim/não & $\begin{array}{l}\text { Abastecimento de energia } \\
\text { elétrica - Rede pública }\end{array}$ \\
\hline & ID_ENERGIA_GERADOR & $\begin{array}{l}\text { Padrão } \\
\text { Inep }\end{array}$ & $\operatorname{sim} /$ não & sim/não & $\begin{array}{l}\text { Abastecimento de energia } \\
\text { elétrica - Gerador }\end{array}$ \\
\hline & ID_ENERGIA_OUTROS & $\begin{array}{l}\text { Padrão } \\
\text { Inep }\end{array}$ & sim/não & sim/não & $\begin{array}{l}\text { Abastecimento de energia } \\
\text { elétrica - Outros (Energia } \\
\text { alternativa) }\end{array}$ \\
\hline & $\begin{array}{l}\text { ID_ENERGIA } \\
\text { INEXISTENTEE }\end{array}$ & $\begin{array}{l}\text { Padrão } \\
\text { Inep }\end{array}$ & sim/não & sim/não & $\begin{array}{l}\text { Abastecimento de energia } \\
\text { elétrica - Inexistente }\end{array}$ \\
\hline \multirow{3}{*}{ ID_ESGOTO } & $\begin{array}{l}\text { ID_ESGOTO_REDE_ } \\
\text { PUBLICA }\end{array}$ & $\begin{array}{l}\text { Padrão } \\
\text { Inep }\end{array}$ & sim/não & sim/não & $\begin{array}{l}\text { Esgoto sanitário - Rede } \\
\text { pública }\end{array}$ \\
\hline & ID_ESGOTO_FOSSA & $\begin{array}{l}\text { Padrão } \\
\text { Inep }\end{array}$ & sim/não & sim/não & Esgoto sanitário - Fossa \\
\hline & ID_ESGOTO_INEXISTENTE & $\begin{array}{l}\text { Padrão } \\
\text { Inep }\end{array}$ & sim/não & sim/não & Esgoto sanitário - Inexistente \\
\hline \multirow{5}{*}{$\begin{array}{l}\text { ID } \\
\text { SANITARIO }\end{array}$} & $\begin{array}{l}\text { ID_SANITARIO_FORA_ } \\
\text { PREDIO }\end{array}$ & $\begin{array}{l}\text { Padrão } \\
\text { Inep }\end{array}$ & sim/não & sim/não & $\begin{array}{l}\text { Dependências existentes na } \\
\text { escola - Sanitário fora do } \\
\text { prédio }\end{array}$ \\
\hline & $\begin{array}{l}\text { ID_SANITARIO_DENTRO_ } \\
\text { PREDIO }\end{array}$ & $\begin{array}{l}\text { Padrão } \\
\text { Inep }\end{array}$ & sim/não & sim/não & $\begin{array}{l}\text { Dependências existentes na } \\
\text { escola - Sanitário dentro do } \\
\text { prédio }\end{array}$ \\
\hline & ID_SANITARIO_EI & $\begin{array}{l}\text { Padrão } \\
\text { Inep }\end{array}$ & $\operatorname{sim} /$ não & sim/não & $\begin{array}{l}\text { Dependências existentes na } \\
\text { escola - Sanitário dentro do } \\
\text { prédio }\end{array}$ \\
\hline & ID_SANITARIO_PNE & $\begin{array}{l}\text { Padrão } \\
\text { Inep }\end{array}$ & sim/não & sim/não & $\begin{array}{l}\text { Dependências existentes na } \\
\text { escola - Sanitário adequado } \\
\text { a alunos com deficiência ou } \\
\text { mobilidade reduzida }\end{array}$ \\
\hline & ID_BANHEIRO_CHUVEIRO & $\begin{array}{l}\text { Padrão } \\
\text { Inep }\end{array}$ & sim/não & sim/não & $\begin{array}{l}\text { Dependências existentes } \\
\text { na escola - Banheiro com } \\
\text { chuveiro }\end{array}$ \\
\hline \multirow{2}{*}{$\begin{array}{l}\text { ID_QUADRA_ } \\
\text { ESPORTES }\end{array}$} & $\begin{array}{l}\text { ID_QUADRA_ESPORTES_ } \\
\text { COBERTA }\end{array}$ & $\begin{array}{l}\text { Padrão } \\
\text { Inep }\end{array}$ & sim/não & sim/não & $\begin{array}{l}\text { Dependências existentes na } \\
\text { escola - Quadra de esportes } \\
\text { coberta }\end{array}$ \\
\hline & $\begin{array}{l}\text { ID_QUADRA_ESPORTES_ } \\
\text { DESCOBERTA }\end{array}$ & $\begin{array}{l}\text { Padrão } \\
\text { Inep }\end{array}$ & sim/não & sim/não & $\begin{array}{l}\text { Dependências existentes na } \\
\text { escola - Quadra de esportes } \\
\text { descoberta }\end{array}$ \\
\hline \multirow{2}{*}{ ID_PATIO } & ID_PATIO_COBERTO & $\begin{array}{l}\text { Padrão } \\
\text { Inep }\end{array}$ & sim/não & sim/não & $\begin{array}{l}\text { Dependências existentes na } \\
\text { escola - Pátio Coberto }\end{array}$ \\
\hline & ID_PATIO_DESCOBERTO & $\begin{array}{l}\text { Padrão } \\
\text { Inep }\end{array}$ & $\operatorname{sim} /$ não & sim/não & $\begin{array}{l}\text { Dependências existentes na } \\
\text { escola - Pátio Descoberto }\end{array}$ \\
\hline
\end{tabular}


QUADRO B.1 - Composição, categorização e descrição de cada uma das variáveis que foram criadas para compor os Indicadores de Qualidade da Infraestrutura Escolar

(conclusão)

\begin{tabular}{|c|c|c|c|c|c|}
\hline $\begin{array}{l}\text { NOME DA } \\
\text { NOVA VARIÁVEL }\end{array}$ & $\begin{array}{l}\text { VARIÁVEIS QUE A } \\
\text { COMPÕEM }\end{array}$ & ORIGEM & $\begin{array}{c}\text { TIPO } \\
\text { ORIGINAL }\end{array}$ & $\begin{array}{l}\text { NOVO } \\
\text { TIPO }\end{array}$ & DESCRIÇÃO \\
\hline \multirow{2}{*}{$\begin{array}{l}\text { ID_ACESSO__ } \\
\text { INTERNET }\end{array}$} & ID_INTERNET & $\begin{array}{l}\text { Padrão } \\
\text { Inep }\end{array}$ & $\operatorname{sim} /$ não & sim/não & Acesso à internet \\
\hline & ID_BANDA_LARGA & $\begin{array}{l}\text { Padrão } \\
\text { Inep }\end{array}$ & $\operatorname{sim} /$ não & sim/não & Internet Banda Larga \\
\hline \multirow{2}{*}{$\begin{array}{l}\text { ID } \\
\text { COMPUTADORES_ } \\
\text { OUTRO }\end{array}$} & NUM_COMPUTADORES & $\begin{array}{l}\text { Padrão } \\
\text { Inep }\end{array}$ & quant. & $\operatorname{sim} /$ não & $\begin{array}{l}\text { Quantidade de computadores } \\
\text { na escola (transformada para } \\
\text { indicar apenas a presença ou } \\
\text { não do equipamento) }\end{array}$ \\
\hline & $\begin{array}{c}\text { NUM_COMP } \\
\text { ADMINISTRATIVOS }\end{array}$ & $\begin{array}{l}\text { Padrão } \\
\text { Inep }\end{array}$ & quant. & $\operatorname{sim} /$ não & $\begin{array}{l}\text { Quantidade de computadores } \\
\text { de uso administrativo } \\
\text { (transformada para indicar } \\
\text { apenas a presença ou não do } \\
\text { equipamento) }\end{array}$ \\
\hline
\end{tabular}

Fonte: Tabulação própria com base na descrição das variáveis do Censo Escolar da Educação Básica do Inep.

QUADRO B.2 - Relação das variáveis de infraestrutura que não foram utilizadas na composição dos Indicadores de Qualidade da Infraestrutura Escolar

\begin{tabular}{|c|c|c|c|c|}
\hline NOME DA VARIÁVEL & ORIGEM & $\begin{array}{c}\text { TIPO } \\
\text { ORIGINAL }\end{array}$ & DESCRIÇÃO & MOTIVO DO DESCARTE \\
\hline NUM_SALAS_EXISTENTES & $\begin{array}{l}\text { Padrão } \\
\text { Inep }\end{array}$ & quant. & $\begin{array}{l}\text { Número de salas de aula } \\
\text { existentes na escola }\end{array}$ & \multirow{2}{*}{$\begin{array}{l}\text { Não se relacionam diretamente } \\
\text { com um item de qualidade. } \\
\text { Seria necessário avaliar, } \\
\text { por exemplo, número de } \\
\text { turmas, horários, número de } \\
\text { profissionais, etc. }\end{array}$} \\
\hline NUM_SALAS_UTILIZADAS & $\begin{array}{l}\text { Padrão } \\
\text { Inep }\end{array}$ & quant. & $\begin{array}{l}\text { Número de salas utilizadas } \\
\text { como salas de aula (dentro e } \\
\text { fora do prédio) }\end{array}$ & \\
\hline ID_LAVANDERIA & $\begin{array}{l}\text { Padrão } \\
\text { Inep }\end{array}$ & sim/não & $\begin{array}{l}\text { Dependências existentes na } \\
\text { escola - Lavanderia }\end{array}$ & \multirow{3}{*}{$\begin{array}{l}\text { Não se relacionam diretamente } \\
\text { com um item de qualidade. }\end{array}$} \\
\hline ID_ALOJAM_ALUNO & $\begin{array}{l}\text { Padrão } \\
\text { Inep }\end{array}$ & sim/não & $\begin{array}{l}\text { Dependências existentes na } \\
\text { escola - Alojamento de aluno }\end{array}$ & \\
\hline ID_ALOJAM_PROFESSOR & $\begin{array}{l}\text { Padrão } \\
\text { Inep }\end{array}$ & sim/não & $\begin{array}{l}\text { Dependências existentes } \\
\text { na escola - Alojamento de } \\
\text { professor }\end{array}$ & \\
\hline ID_SALA_LEITURA & $\begin{array}{l}\text { Padrão } \\
\text { Inep }\end{array}$ & sim/não & $\begin{array}{l}\text { Dependências existentes na } \\
\text { escola - Biblioteca/Sala de } \\
\text { leitura }\end{array}$ & $\begin{array}{l}\text { Como só é identificado em } \\
\text { complemento à biblioteca, não } \\
\text { se pode inferir diretamente } \\
\text { se há ou não esse espaço no } \\
\text { estabelecimento. }\end{array}$ \\
\hline
\end{tabular}

Fonte: Tabulação própria com base na descrição das variáveis do Censo Escolar da Educação Básica do Inep. 
